Research Article

J Exp Clin Med

2021; 38(4): 451-456

doi: $10.52142 /$ omujecm.38.4.9

\title{
The investigation survey of inguinal hernia operation techniques preferred by pediatric surgeons in Turkey

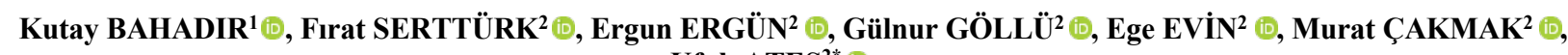 Ufuk ATEŞ ${ }^{2 *}$ (i)
}

\author{
${ }^{1}$ Department of Pediatric Surgery, Kırıkkale Yüksek İhtisas Hospital, Kırıkkale, Turkey \\ ${ }^{2}$ Department of Pediatric Surgery, Ankara University School of Medicine, Ankara, Turkey
}

\begin{abstract}
\begin{tabular}{lllll}
\hline Received: 01.03.2021 & $\bullet$ & Accepted/Published Online: 07.03.2021 & Final Version: 30.08 .2021 \\
\hline
\end{tabular}
\section{Abstract}

In inguinal hernia, standard procedure has been considered open repair for a long time, the number of pediatric surgeons who prefer laparoscopic techniques is increasing day by day. In this study, it was aimed to determine how pediatric surgeons in our country approach patients with inguinal hernia and manage the treatment process. Controversial issues on inguinal hernia repair were identified and a questionnaire was prepared to reveal the current situation. The questionnaire was delivered to members of Turkish Association of Pediatric Surgery on the official website of the association. The survey was directed to 420 people, 92 people returned with the answers to the questionnaire. Thirty-six of the surgeons prefer the laparoscopic method for inguinal hernia repair. The reason for choosing open surgery was questioned, the most frequent answer was to be more experienced and to have more cumulative knowledge on open repair method. According to survey, the greatest advantage of laparoscopy was stated to be the better evaluation of the contralateral inguinal canal ( $n=16$, $\% 44.4)$. Twelve of surgeons who performed laparoscopic treatment in the selection of patients stated that gender is important and prefer laparoscopic surgery for female patients. Thirty percent $(n=11)$ of the participants stated that they prefer laparoscopy in patients between 3 months and 13 years old, while the rest prefer laparoscopy at all ages. In conclusion thirty nine percent of surgeons in Turkey prefer laparoscopic repair. Open repair is still preferred in our country. There is still no consensus on perfect method and patient selection yet.
\end{abstract}

Keywords: hernia, inguinal, laparoscopy, surveys and questionnaires

\section{Introduction}

Inguinal hernia $(\mathrm{IH})$ is one of the most common surgical pathologies treated by pediatric surgeons (1). Surgical treatment is required in children since $\mathrm{IH}$ can result in incarceration, strangulation, and intestinal ischemia (1). For years, standard surgical technique in IH for children has been considered the traditional open repair because of its low complication and recurrence rates (2). However, some studies reported that the results of laparoscopic surgery are comparable in terms of complications and recurrence (3). A guideline regarding which operation technique to prefer has not been established yet (4).

The reported advantages of laparoscopic hernia repair are better exposure, more accurate evaluation of the contralateral inguinal canal, minimal dissection, better cosmetic outcome. Recurrence and complication rates are found to be comparable and close to open repair (5). Especially after defining the PIRS method, laparoscopic IH repair is becoming more and more popular among pediatric surgeons (6).

Although both methods have advantages and disadvantages, there is no consensus regarding which method should be preferred yet (7). In this study, it was aimed to determine how pediatric surgeons in our country approach their patients with IH and manage the treatment process.

\section{Materials and methods}

After the literature review, controversial issues between laparoscopic repair and open repair in IH repair were identified and to clarify the situation, a questionnaire was prepared to reveal the current situation. The questionnaire was delivered to members of Turkish Association of Pediatric Surgery (420 pediatric surgeons) on the official website of the association. 92 surgeons participated in the study and the responses were evaluated. Survey outputs were evaluated with Microsoft Excel. Ethical approval for this study was obtained from Ankara University Faculty of Medicine Ethical Committee (İ3-183-20).

\section{Results}

Of the 92 respondents, 86 were pediatric surgeons and six were pediatric urologists. Forty percent of the participants $(n=37)$ have more than 16 years of surgical experience. $80 \%$ of the participants $(n=74)$ are performing minimally invasive surgery (MIS). Among the participants, 39\% $(n=36)$ of them 
prefer the laparoscopic method for IH repair. This number accounts for about half of those who are performing laparoscopic surgery.

For surgeons who prefer the open method, the most important reason why they do not prefer laparoscopy is that they think laparoscopic treatment is not superior. (78\%, $\mathrm{n}=44$ ). In a multi-answer question about why they prefer open surgery, the most common answer was to have more experience and to have more cumulative information about open surgery. The most common answer to the question about the disadvantages of the laparoscopic method was that open surgery is an extra abdominal procedure, whereas laparoscopy requires intraabdominal intervention.

$66 \%(n=24)$ of surgeons who preferred laparoscopic surgery had been using laparoscopic repair in their clinical practice for 0-5 years. The most preferred laparoscopic method was percutaneous internal ring suturization (PIRS) $(77 \%(n=28))$. According to survey, the greatest advantage of laparoscopy was the better evaluation of the contralateral inguinal canal $(n=16,44.4 \%)$. Twelve of surgeons $(33 \%)$ who performed laparoscopic treatment in the selection of patients stated that gender is important and prefer laparoscopic surgery for female patients. Thirty percent $(n=11)$ of the participants stated that they prefer laparoscopy in patients between three months and 13 years old, while the rest prefer laparoscopy at all ages. The responds revealed that the vast majority do not need additional ports $(70 \%, n=25)$. The most frequent reason for those who need an additional port was for peritoneal manipulation.

Surgeons who prefer laparoscopic approach stated that in $39 \%(n=14)$ of their surgeries the ventilation was provided by laryngeal mask and $61 \% \quad(n=22)$ was provided by endotracheal intubation in anesthesical management. Spinal anesthesia was not preferred by any of the participants. Many of the participants $80 \% \quad(n=29)$ preferred non-absorbable suture material (nylon) and polyethylene terephthalate suture (ethibond) was most frequently preferred six and 23, respectively. Hydrodissection was preferred by 12 of the surgeons (33\%). Nineteen of the surgeons (52\%) prefer redo laparoscopic method for treatment in patients who completed their laparoscopic first operation and subsequently developed recurrence. Most of surgeons $(n=24,66 \%)$ ) repair the contralateral patent processus vaginal detected during surgery. Detailed information on applied questionnaire and answers were presented in Table 1.

Table 1. Detailed information on applied questionnaire; the questions and answers with the percentages

\begin{tabular}{|l|c|}
\hline Questions & $\begin{array}{c}\text { Answers and } \\
\text { Percentages } \\
(\%)\end{array}$ \\
\hline Specialty & $86(\% 93.48)$ \\
\hline Pediatric Surgeon & $6(\% 6.52)$ \\
\hline Pediatric Urologist & \\
\hline Experience (duration) &
\end{tabular}

\begin{tabular}{|c|c|}
\hline $0-5$ years & $17(\% 18.47)$ \\
\hline $6-10$ years & $16(\% 17.40)$ \\
\hline $11-15$ years & $22(\% 23.91)$ \\
\hline$>16$ years & $37(\% 40.22)$ \\
\hline \multicolumn{2}{|l|}{ Institutional Information } \\
\hline University Hospital & $33(\% 35.86)$ \\
\hline Training and Research Hospital & $32(\% 34.78)$ \\
\hline Private Hospital & $16(\% 17.39)$ \\
\hline Public Hospital & $11(\% 11.95)$ \\
\hline \multicolumn{2}{|l|}{ Practical Use of Minimally Invasive Surgery } \\
\hline In Use & $74(\% 80.43)$ \\
\hline Not In Use & $18(\% 19.56)$ \\
\hline \multicolumn{2}{|c|}{ Experience of Minimal Invasive Surgery (if available) } \\
\hline $0-5$ years & $22(\% 29.73)$ \\
\hline $6-10$ years & $26(\% 35.13)$ \\
\hline $11-15$ years & $18(\% 24.32)$ \\
\hline$>16$ years & $8(\% 10.81)$ \\
\hline \multicolumn{2}{|c|}{$\begin{array}{l}\text { Performing diagnostic contralateral laparoscopy in open IH } \\
\text { repair }\end{array}$} \\
\hline Yes & $23(\% 25)$ \\
\hline No & $69(\% 75)$ \\
\hline \multicolumn{2}{|c|}{$\begin{array}{l}\text { If Performing. Contralateral Laparoscopy Experience } \\
\text { (duration) }\end{array}$} \\
\hline $0-5$ years & $10(\% 43.47)$ \\
\hline $6-10$ years & $7(\% 30.43)$ \\
\hline $11-15$ years & $3(\% 13.05)$ \\
\hline$>16$ years & $3(\% 13.05)$ \\
\hline \multicolumn{2}{|l|}{ Practical Use of Laparoscopic IH Repair } \\
\hline In Use & $36(\% 39.13)$ \\
\hline Not In Use & $56(\% 60.86)$ \\
\hline \multicolumn{2}{|c|}{ Reasons for Not Using Laparoscopic IH Repair } \\
\hline Equipment Shortage & $5(\% 8.92)$ \\
\hline Lack of Experience & $7(\% 12.5)$ \\
\hline Open Surgery Preferance & $44(\% 78.57)$ \\
\hline \multicolumn{2}{|l|}{ Reasons for Open Surgery Preference * } \\
\hline Lack of Laparoscopic Experience & $12(\% 10.15)$ \\
\hline Equipment Shortage & $5(\% 4.1)$ \\
\hline Extra abdominal Placement & $33(\% 28.9)$ \\
\hline $\begin{array}{l}\text { Enable to evaluate the inguinal canal and } \\
\text { funiculus spermaticus by feeling the tissue }\end{array}$ & $28(\% 24.5)$ \\
\hline Experience and Cumulative Knowledge & $36(\% 32)$ \\
\hline \multicolumn{2}{|l|}{ Limitations of Laparoscopic Repair * } \\
\hline Peritoneum Invasion & $37(\% 39.4)$ \\
\hline $\begin{array}{l}\text { Cord and its elements are more likely to be } \\
\text { damaged }\end{array}$ & $27(\% 28.7)$ \\
\hline Lack of Experience & $7(\% 7.5)$ \\
\hline Equipment Shortage & $5(\% 5.3)$ \\
\hline $\begin{array}{l}\text { Causes related to anesthesia and operating } \\
\text { room conditions }\end{array}$ & $18(\% 19.1)$ \\
\hline \multicolumn{2}{|c|}{ Laparoscopic IH Repair Experience (duration) } \\
\hline $0-5$ years & $24(\% 66.66)$ \\
\hline $6-10$ years & $10(\% 27.77)$ \\
\hline $11-15$ years & $1(\% 2.77)$ \\
\hline$>16$ years & $1(\% 2.77)$ \\
\hline \multicolumn{2}{|c|}{ Number of Patients Undergoing Laparoscopic IH Repair } \\
\hline $0-25$ patients & $20(\% 55.55)$ \\
\hline $25-50$ patients & $5(\% 13.88)$ \\
\hline $50-100$ patients & $2(\% 5.55)$ \\
\hline$>100$ patients & $9(\% 25)$ \\
\hline \multicolumn{2}{|l|}{ The Method Used in Laparoscopic IH Repair } \\
\hline Hernia Repair with 3 Ports & $5(\% 13.88)$ \\
\hline Single Port Hernia Repair & $2(\% 5.55)$ \\
\hline $\begin{array}{l}\text { PIRS (Percutaneous Internal Ring } \\
\text { Suturization) }\end{array}$ & $28(\% 77.77)$ \\
\hline $\begin{array}{l}\text { Burnia Technique (Cauterization of the } \\
\text { Circumference of the Hernia Sac) }\end{array}$ & $1(\% 3.6)$ \\
\hline
\end{tabular}




\begin{tabular}{|c|c|}
\hline \multirow{2}{*}{\multicolumn{2}{|c|}{$\begin{array}{l}\text { Repair with Patch } \\
\text { Laparoscopic IH Repair Preferred Situations * }\end{array}$}} \\
\hline & \\
\hline Emergent Situations & $16(\% 11.6)$ \\
\hline Elective Situations & $32(\% 23)$ \\
\hline Female Patients & $27(\% 19.5)$ \\
\hline Male Patients & $9(\% 6.5)$ \\
\hline Based on family's preference & $19(\% 13.6)$ \\
\hline Age based & $11(\% 7.9)$ \\
\hline Based on equipment & $13(\% 9.3)$ \\
\hline For resident training purposes & $12(\% 8.6)$ \\
\hline \multicolumn{2}{|c|}{$\begin{array}{l}\text { The Biggest Advantage of Laparoscopic IH Repair Over } \\
\text { Open Surgery }\end{array}$} \\
\hline Being minimally invasive surgery & $7(\% 19.44)$ \\
\hline Not being touched of cord and elements & $9(\% 25)$ \\
\hline Comfortable viewing of the contralateral side & $16(\% 44.44)$ \\
\hline Cosmetic superiority & $4(\% 11.11)$ \\
\hline \multicolumn{2}{|l|}{ Disadvantages of Open IH Repair } \\
\hline $\begin{array}{l}\text { Cord and its elements exposed to tactile } \\
\text { trauma }\end{array}$ & $13(\% 36.11)$ \\
\hline $\begin{array}{l}\text { Failure to control the contralateral side all the } \\
\text { time }\end{array}$ & $19(\% 52.77)$ \\
\hline Cosmetic reasons & $1(\% 2.77)$ \\
\hline Surgical difficulty in some patient groups & $3(\% 8.33)$ \\
\hline \multicolumn{2}{|c|}{ Is patient gender a criterion to choose laparoscopic repair? } \\
\hline Yes. it is. & $12(\% 33.3)$ \\
\hline No. it is not. & $24(\% 66.6)$ \\
\hline \multicolumn{2}{|l|}{ If yes, what gender to choose? } \\
\hline Female & $12(\% 100)$ \\
\hline Male & $0(\% 0)$ \\
\hline \multicolumn{2}{|l|}{ Preference of laparoscopic IH repair age group } \\
\hline $0-3$ months & $0(\% 0)$ \\
\hline 3 months -13 years & $11(\% 30.55)$ \\
\hline $13-18$ years & $0(\% 0)$ \\
\hline All of them & $25(\% 69.44)$ \\
\hline \multicolumn{2}{|c|}{$\begin{array}{l}\text { Additional trocar requirement other than camera trocar in } \\
\text { IH repair with laparoscopic PIRS technique }\end{array}$} \\
\hline ت & $7(\% 19.44)$ \\
\hline No & $25(\% 69.44)$ \\
\hline Sometimes & $4(\% 11.1)$ \\
\hline \multicolumn{2}{|l|}{ If yes. the reason of using additional trocar } \\
\hline Peritoneum Manipulation & $6(\% 85.71)$ \\
\hline Inguinal Canal Circumference Cauterization & $1(\% 14.28)$ \\
\hline \multicolumn{2}{|c|}{ Anesthesia technique used in laparoscopic IH surgery } \\
\hline Laryngeal Mask & $14(\% 38.88)$ \\
\hline Intubation & $22(\% 61.11)$ \\
\hline Spinal anesthesia & $0(\% 0)$ \\
\hline \multicolumn{2}{|l|}{ Suture material used in laparoscopic IH repair } \\
\hline Nylon (non-absorbent monofilament suture) & $6(\% 16.66)$ \\
\hline $\begin{array}{l}\text { Ethibond (non-absorbent } \\
\text { polyethyleneterephthalate suture) }\end{array}$ & $23(\% 63.88)$ \\
\hline Vicryl (absorbable polyglycolicacid suture) & $5(\% 13.88)$ \\
\hline PDS (absorbable polydioxone suture) & $2(\% 5.55)$ \\
\hline \multicolumn{2}{|l|}{ Hydrodissection Application } \\
\hline Yes & $12(\% 33.33)$ \\
\hline No & $24(\% 66.66)$ \\
\hline \multicolumn{2}{|c|}{$\begin{array}{l}\text { Surgical preference in patients with recurrency after } \\
\text { laparoscopic repair }\end{array}$} \\
\hline Open repair & $17(\% 47.22)$ \\
\hline Laparoscopic repair & $19(\% 52.77)$ \\
\hline \multicolumn{2}{|c|}{$\begin{array}{l}\text { The complication that the surgeons experience or are afraid } \\
\text { of laparoscopic IH operation * }\end{array}$} \\
\hline Bleeding and hematoma & $23(\% 34.5)$ \\
\hline Cord injury & $14(\% 20.9)$ \\
\hline Abdominal organ injury & $8(\% 11.9)$ \\
\hline İleus & $3(\% 4.5)$ \\
\hline Recurrence & $18(\% 26.8)$ \\
\hline Anesthetic-related complication & $1(\% 1.4)$ \\
\hline
\end{tabular}

Laparoscopic repair of PPV detected on the contralateral side during laparoscopic repair

Yes $24(\% 66.6)$

No $12(\% 33.3)$

IH: Inguinal Hernia

Questions marked with “*” have multiple answers

\section{Discussion}

The first minimally invasive intervention in $\mathrm{IH}$ in children was described by Gans et al. in 1971; it was the examination of the contralateral inguinal canal from the hernia sac (8). With the minimally invasive approach and the development of instruments, laparoscopic IH repair has started to be applied more frequently in children (8). Although there are different surgical techniques described, this frequency has increased gradually with the definition of transumbilical single-port methods (9).

When the survey results were taken into consideration, Turkey seems to be more common in open surgery as the preferred method. In their survey study Zani et al. concluded that many surgeons preferred open method to laparoscopic method, but the number of surgeons who preferred laparoscopic method has been increased in recent years (8). In USA, $13 \%$ of $\mathrm{IH}$ cases in children were performed with laparoscopic methods between 2009 and 2014 (10). Between 2010 and 2016, the rate of IHs performed laparoscopically was $37 \%$ (11). When the cases performed between 2005 and 2017 were evaluated in the cohort study conducted by Nakashima et al. (3), it was observed that more than $50 \%$ of the cases performed in the last two years were completed laparoscopically. As a result of our study, it has been observed that most surgeons who prefer laparoscopy have recently adopted this method. These data may indicate that percentage of those who will prefer laparoscopic surgery may increase. Although the open method is preferred more frequently, the rate of surgeons who prefer laparoscopy is higher in Turkey comparing other survey and cohort studies $(3,10,11)$.

In the other survey study by Zani et al. (8); surgeons who prefer the open method defined the most important advantages as low recurrence probability, less risk of injury of an abdominal organ, testicular vascular structures or spermatic cord and shorter surgery time. On the other hand, surgeons who prefer laparoscopic repair methods defined the advantages as the low possibility of occurrence of contralateral metachronous hernia, better cosmetic results, easier technique, lower risk of injury of testicular vessel and cord structures, and less postoperative pain (8). The results appear to be like our study. The most important advantage that was stated by the respondents was better evaluation of the contralateral side (44.4\%). Other advantages mentioned were safety of the cord and its elements (25\%), minimally invasive procedure (19.44\%) and better cosmetic results (11.11\%), respectively. In a meta-analysis including three randomized controlled trials and four observational studies (a total of 
1543 laparoscopic approaches, 657 open approaches), laparoscopic repair has similar results with open repair for these concerns (12). The same meta-analysis shows that laparoscopy has better results in terms of metachron contralateral hernia and cosmetics (12). A randomized controlled trial evaluating laparoscopic repair, shows shorter surgery and discharge time, lower recurrence rate, lower testicular complication rate (5). There are systemic reviews showing that laparoscopy is superior to the open method in terms of less early complications and shorter anesthesia and operation time, especially for bilateral cases (13). On the other hand, it was seen that extraperitoneal repair methods are faster in unilateral cases (4).

In our study, lack of experience was observed as another reason stated by the participants for not choosing laparoscopy $(n=7,12 \%)$. In a national survey study in Denmark, most surgeons preferred open method for children under 12, while one in 7 was using both open and laparoscopic methods depending on the situation (14). In patients between 13-18 years old, it was seen that while two-thirds of surgeons prefer only open repair, $6 \%$ prefer only laparoscopic repair, and the rest were using both methods (14). Considering the reasons of the surgeons for not preferring the laparoscopic method, the most common reason is seen as the lack of experience (14). It has been shown that the experience of the surgeon is important in laparoscopy and the learning process may be longer in laparoscopy against open repair (15). It has been shown that learning process for advanced laparoscopic techniques is faster for surgeons who specialized laparoscopy (16). Surgeon's experience on performing laparoscopic procedures for other pathologies is important for the process. On the other hand, the number of cases that a surgery resident needed to complete without supervision was found to be much higher (16). The survey study conducted by Zani et al. (8) and another study of Bertozzi et. al. (17) stated that number of cases required to perform laparoscopic inguinal hernia repair safely without supervision was 20 cases. However, the treatment of transumbilical single-port laparoscopic IH (PIRS) has been found to be much easier to learn and apply due to no need for classical three-port laparoscopy maneuvers (18). As a result, learning process and competent practical use of the PIRS method may be faster than other techniques.

The participants preferred both open and laparoscopic surgery stated that the risk of damaging vas deferens and testicular vascular structures is one of the reasons for not choosing other methods. Although information showing how future fertility is affected after inguinal hernia surgery in children is not sufficient, it may be predicted that complications may arise due to interventions on vasal and spermatic vessels during surgery (19). In the open method, these structures are exposed to surgical manipulation and trauma. In the repair done with a single port, the cord and surrounding structures can be removed from the peritoneum by hydrodissection method, and the operation can be completed with a single safe hole (18). With this simple method, a safe and truly minimally invasive repair can be done by protecting the cord and surrounding tissues from manipulation and trauma (18). One third of the participants in this study use the hydrodissection method.

In our study, it was found that $66 \%(n=24)$ of the surgeons preferring laparoscopic approach if the metachronous hernias were detected and the metachronous hernias were repaired in the same session. Although the probability of contralateral metachronous IH is $4-32 \%$, there is no consensus among pediatric surgeons regarding the approach for checking metachronous contralateral inguinal hernia (20). Transinguinal laparoscopic evaluation appears to be effective in detecting contralateral hernia (21). Transinguinal laparoscopy on the contralateral non-hernia side is highly effective for preventing an unnecessary operation that may damage the cord and surrounding structures and the risk of re-anesthesia that may arise in the event of a subsequent contralateral metachron inguinal hernia (21). There are publications showing that contralateral PPV was detected in $38 \%$ of patients with unilateral IH $(20,21)$. Considering the current risks of contralateral exploration, since not every PPV is herniated, the application of this method is controversial (1).

Among the surgeons who perform laparoscopic surgery, $44 \%$ of them prefer laparoscopic treatment in emergency situations (such as incarceration). In incarcerated hernia repair, the edema of the operation area makes the operation far more difficult in the open approach (22). This disadvantage is eliminated in laparoscopy since the edema does not cause such problem. One of the advantages of laparoscopy in incarcerated cases is that it facilitates the reduction of herniated structures with the created pneumoperitoneum (23). At the same time, the condition of the incarcerated organs may be evaluated (24). Although surgeons mostly did not prefer laparoscopy for incarceration in our study, Nah et al. described the advantages of laparoscopic approach as less recurrence of incarceration and a decreased rate of potential complications such as vascular injury (25).

Laparoscopy in recurrent cases is also a matter of debate among surgeons. In this survey study, almost half of the surgeons who preferred laparoscopic approach, preferred open method as the treatment of recurrences after laparoscopic repair. On the other hand, there are studies supporting laparoscopic repair, especially in male patients, for recurrences after open repair (9). In the open approach, there may be an increased risk of damaging vas deferens and testicular vascular structures especially for recurrent cases (26). It was stated that laparoscopic approach reduced the risk of open re-surgery (26).

In the present study, it is seen that endotracheal intubation 
is applied more frequently in routine anesthesiology practice for laparoscopic procedures. Extraperitoneal and intraperitoneal methods can be preferred for hernia repair, but extraperitoneal method is preferred more frequently by pediatric surgeons due to its effectiveness and easy application (27). When the groups of patients who underwent laparoscopic IH repair using laryngeal mask airway (LMA) and endotracheal tube were compared, duration of anesthesia time was shorter in the LMA group (28). The fast and reliable PIRS method makes it safe to perform anesthesia with LMA (28). There are studies showing that the use of laryngeal mask is associated with less bronchospasm, laryngospasm, cough, and edema (28). Increasing experience and shortening the operation time will allow LMA to be used in anesthesia, thereby reducing the anesthetic complications of patients and the comorbidities that may occur.

While selecting the suture material to be used in the operation, the number of participants who preferred the nonabsorbable material was found to be higher in our study. There are very few studies comparing absorbable and nonabsorbable suture materials in IH repair. In a study of 300 cases, no significant difference was found between the two materials in terms of recurrence (29). Other studies have shown that the rate of recurrence was lower when nonabsorbable suture material was used (30). However, previously published studies have shown that better results can be obtained with more surgical experience by using absorbable suture material (31).

In conclusion, thirty nine percent of surgeons in Turkey prefer laparoscopic repair. Open repair is still the preferred method in our country. There is no consensus about method and patient selection yet. As the level of scientific evidence increases and the method becomes more frequent, we predict that laparoscopic inguinal hernia repair will be preferred more frequently than today.

\section{Conflict of interest}

There is no conflict of interest between authors.

\section{Funding}

No funding was received for this study.

\section{Acknowledgement}

We show our acknowledgments to members of Turkish Association of Pediatric Surgery for attending this survey study.

\section{References}

1. Ron O, Eaton S, Pierro A. Systematic review of the risk of developing a metachronous contralateral inguinal hernia in children. Br J Surg. 2007; 94(7): 804-11. doi: 10.1002/bjs.5856.

2. Erdogan D, Karaman I, Aslan MK, Karaman A, Cavusoglu YH. Analysis of 3,776 pediatric inguinal hernia and hydrocele cases in a tertiary center. J Pediatr Surg. 2013; 48(8): 1767-72. doi: 10.1016/j.jpedsurg.2012.09.048.

3. Nakashima M, Ide K, Kawakami K. Laparoscopic versus open repair for inguinal hernia in children: A retrospective cohort study. Surg Today. 2019; 49(12):1044-50. doi: 10.1007/s00595019-01847-0.

4. Olesen CS, Andresen K, Oberg S, Rosenberg J. Laparoscopic versus open repair of groin hernias in children: A systematic review and meta-analysis. Surg Endosc. 2019; 33(7): 2050-60. doi: 10.1007/s00464-019-06740-y.

5. Shalaby R, Ibrahem R, Shahin M, Yehya A, Abdalrazek M, Alsayaad I, et al. Laparoscopic Hernia Repair versus Open Herniotomy in Children: A Controlled Randomized Study. Minim Invasive Surg. 2012; 2012: 484135. doi: 10.1155/2012/484135.

6. Patkowski D, Czernik J, Chrzan R, Jaworski W, Apoznański W. Percutaneous internal ring suturing: a simple minimally invasive technique for inguinal hernia repair in children. J Laparoendosc Adv Surg Tech A. 2006; 16(5):513-7. doi: 10.1089/lap.2006.16.513.

7. Dreuning K, Maat S, Twisk J, van Heurn E, Derikx J. Laparoscopic versus open pediatric inguinal hernia repair: stateof-the-art comparison and future perspectives from a metaanalysis. Surg Endosc. 2019;33(10):3177-91. doi: 10.1007/s00464-019-06960-2.

8. Zani A, Eaton S, Hoellwarth M, Puri P, Tovar J, Fasching G, et al. Management of pediatric inguinal hernias in the era of laparoscopy: Results of an international survey. Eur J Pediatr Surg. 2014; 24(1): 9-13. doi: 10.1055/s-0033-1354586.

9. Korkmaz M, Guvenc BH. Comparison of Single-Port Percutaneous Extraperitoneal Repair and Three-Port MiniLaparoscopic Repair for Pediatric Inguinal Hernia. J Laparoendosc Adv Surg Tech A. 2018; 28 (3): 337-42. doi: 10.1089/lap.2016.0223.

10. Chan YY, Durbin-Johnson B, Kurzrock EA. Pediatric inguinal and scrotal surgery - Practice patterns in U.S. academic centers. J Pediatr Surg. 2016; 51(11): 1786-90. doi: 10.1016/j.jpedsurg.2016.07.019.

11. Fujiogi M, Michihata N, Matsui H, Fushimi K, Yasunaga H, Fujishiro J. Outcomes following laparoscopic versus open surgery for pediatric inguinal hernia repair: Analysis using a national inpatient database in Japan. J Pediatr Surg. 2019 Mar;54(3):577-581. doi: 10.1016/j.jpedsurg.2018.03.015.

12. Yang C, Zhang H, Pu J, Mei H, Zheng L, Tong Q. Laparoscopic vs open herniorrhaphy in the management of pediatric inguinal hernia: a systemic review and meta-analysis. J Pediatr Surg. 2011; 46(9): 1824-34. doi: 10.1016/j.jpedsurg.2011.04.001.

13. Esposito C, Escolino M, Turrà F, Roberti $A$, Cerulo M, Farina A, et al. Current concepts in the management of inguinal hernia and hydrocele in pediatric patients in laparoscopic era. Semin Pediatr Surg. 2016; 25(4):232-40. 10.1053/j.sempedsurg.2016.05.006.

14. Olesen CS, Andersen K, Öberg S, Deigaard SL, Rosenberg J. Variations in open and laparoscopic repair of paediatric inguinal hernia. Dan Med J. 2020; 67(4): A12190687. PMID: 32285794.

15. Simons MP, Aufenacker T, Bay-Nielsen M, Bouillot JL, Campanelli G, Conze J, et al. European Hernia Society guidelines on the treatment of inguinal hernia in adult patients. Hernia. 2009; 13(4):343-403. doi: 10.1007/s10029-009-0529-7.

16. Yoshizawa J, Ashizuka S, Kuwashima N, Kurobe M, Tanaka K, Ohashi S, et al. Laparoscopic percutaneous extraperitoneal closure for inguinal hernia: learning curve for attending surgeons and residents. Pediatr Surg Int. 2013; 29(12):1281-5. doi: 10.1007/s00383-013-3337-1.

17. Bertozzi M, Melissa B, Magrini E, Bini V, Appignani A. 
Laparoscopic herniorrhaphy in the pediatric age group: what about the learning curve? J Endourol. 2013; 27(7):840-4. doi: 10.1089/end.2012.0690.

18. Zhou J, Chen $X$, Jiang T. Pediatric inguinal hernia treated by single-port laparoscopic water injection hernia crochet needle. Wideochir Inne Tech Maloinwazyjne. 2020 Mar;15(1):239-244. doi: 10.5114/wiitm.2019.86799.

19. Maillet OP, Garnier S, Dadure C, Bringuier S, Podevin G, Arnaud A, et al. Inguinal hernia in premature boys: should we systematically explore the contralateral side? J Pediatr Surg. 2014; 49(9):1419-23. doi: 10.1016/j.jpedsurg.2014.01.055.

20. Gollu G, Ates U, Bahadir K, Ergun E, Yagmurlu A, Cakmak M, et al. Transinguinal laparoscopic evaluation of contralateral side during unilateral inguinal hernia repair for children. J Pediatr Urol. 2019;15(5): 561.e1-561.e6. doi: 10.1016/j.jpurol.2019.07.006.

21. Lee SL, Sydorak RM, Lau ST. Laparoscopic contralateral groin exploration: is it cost effective? J Pediatr Surg. 2010; 45(4):7935. doi: 10.1016/j.jpedsurg.2009.06.021.

22. Balogh B, Hajnal D, Kovács $T$, Saxena AK. Outcomes of laparoscopic incarcerated inguinal hernia repair in children. $\mathrm{J}$ Minim Access Surg. 2020; 16(1):1-4. doi: 10.4103/jmas.JMAS_84_19.

23. Kaya M, Hückstedt T, Schier F. Laparoscopic approach to incarcerated inguinal hernia in children. J Pediatr Surg. 2006; 41(3):567-9. doi: 10.1016/j.jpedsurg.2005.11.066.

24. Bertozzi M, Marchesini L, Tesoro S, Appignani A. Laparoscopic herniorrhaphy in children. Pediatr Med Chir. 2015; 37(2): pmc.2015.109. doi: 10.4081/pmc.2015.109.

25. Nah SA, Giacomello L, Eaton S, de Coppi P, Curry JI, Drake DP, et al. Surgical repair of incarcerated inguinal hernia in children: laparoscopic or open? Eur J Pediatr Surg. 2011; 21(1):8-11. doi: 10.1055/s-0030-1262793.

26. Zhu H, Li J, Peng X, Alganabi M, Zheng S, Shen C, et al. Laparoscopic Percutaneous Extraperitoneal Closure of the Internal Ring in Pediatric Recurrent Inguinal Hernia. J Laparoendosc Adv Surg Tech A. 2019 Oct;29(10):1297-1301. doi: 10.1089/lap.2019.0119.

27. Shalaby R, Ismail M, Dorgham A, Hefny K, Alsaied G, Gabr K, et al. Laparoscopic hernia repair in infancy and childhood: evaluation of 2 different techniques. J Pediatr Surg. 2010 Nov;45(11):2210-6. doi: 10.1016/j.jpedsurg.2010.07.004.

28. Nevešćanin A, Vickov J, Elezović Baloević S, Pogorelić Z. Laryngeal Mask Airway Versus Tracheal Intubation for Laparoscopic Hernia Repair in Children: Analysis of Respiratory Complications. J Laparoendosc Adv Surg Tech A. 2020 Jan;30(1):76-80. doi: 10.1089/lap.2019.0382.

29. Ozgediz D, Roayaie K, Lee H, Nobuhara KK, Farmer DL, Bratton B, et al. Subcutaneous endoscopically assisted ligation (SEAL) of the internal ring for repair of inguinal hernias in children: report of a new technique and early results. Surg Endosc. 2007 Aug;21(8):1327-31. doi: 10.1007/s00464-0079202-3.

30. Li B, Nie X, Xie H, Gong D. Modified single-port laparoscopic herniorrhaphy for pediatric inguinal hernias: based on 1,107 cases in China. Surg Endosc. 2012 Dec;26(12):3663-8. doi: 10.1007/s00464-012-2396-z.

31. Grimsby GM, Keays MA, Villanueva C, Bush NC, Snodgrass WT, Gargollo PC, et al. Non-absorbable sutures are associated with lower recurrence rates in laparoscopic percutaneous inguinal hernia ligation. J Pediatr Urol. 2015; 11(5): 275.e1-4. doi: 10.1016/j.jpurol.2015.04.029. 